Article

\title{
Superior performance of Co-N/m-C for direct oxidation of alcohols to esters under air
}

\author{
Ning Li a,b, Sensen Shang b, Lianyue Wang ${ }^{b}$, Jingyang Niu a,*, Ying Lv ${ }^{b}$, Shuang Gao b,\# \\ a Henan Key Laboratory of Polyoxometalate Chemistry, College of Chemistry and Chemical Engineering, Henan University, Kaifeng 475004, Henan, China \\ b Dalian National Laboratory for Clean Energy, Dalian Institute of Chemical Physics, Chinese Academy of Sciences, Dalian 116023, Liaoning, China
}

\section{A R T I C L E I N F O}

\section{Article history:}

Received 9 January 2018

Accepted 24 February 2018

Published 5 July 2018

\section{Keywords:}

Cobalt

N-doped

Mesoporous carbon

Esters

Catalysis

\begin{abstract}
A B S T R A C T
A convenient, expeditious, and high-efficiency protocol for the transformation of alcohols into esters using a Co-modified N-doped mesoporous carbon material (Co- $\mathrm{N} / \mathrm{m}-\mathrm{C})$ as the catalyst is proposed. The catalyst was prepared through direct pyrolysis of a macromolecular precursor. The catalyst prepared using a pyrolysis temperature of $900{ }^{\circ} \mathrm{C}$ (labeled Co-N/m-C-900) exhibited the best performance. The strong coordination between the ultra-dispersed cobalt species and the pyridine nitrogen as well as the large area of the mesoporous surface resulted in a high turnover frequency value (107.6 mol methyl benzoate $\mathrm{mol}^{-1} \mathrm{Co} \mathrm{h}^{-1}$ ) for the direct aerobic oxidation of benzyl alcohol to methyl benzoate. This value is much higher than those of state-of-the-art transition-metal-based nanocatalysts reported in the literature. Moreover, the catalyst exhibited general applicability to various structurally diverse alcohols, including benzylic, allylic, and heterocyclic alcohols, achieving the target esters in high yields. In addition, a preliminary evaluation revealed that Co-N/m-C-900 can be used six times without significant activity loss. In general, the process was rapid, simple, and cost-effective.
\end{abstract}

(C) 2018, Dalian Institute of Chemical Physics, Chinese Academy of Sciences. Published by Elsevier B.V. All rights reserved.

\section{Introduction}

Esters are extensively utilized as building blocks in organic synthesis, and they can also be utilized in fine chemicals, agrochemicals, and pharmaceuticals [1]. Conventionally, esterification strategies are based on the reaction of carboxylic acids, anhydrides, acyl halides, or ketenes with alcohols. However, these complicated reaction processes are usually accompanied by reagent waste and the production of a large number of undesired byproducts [1-5]. During recent decades, an enormous amount of effort has been focused on the development of cost-effective and environmentally friendly strategies for ester synthesis [6-14]. Of all the established methodologies, sin- gle-step direct oxidative esterification of alcohols, in which readily available alcohols are used as the starting materials instead of acids or their derivatives, is garnering increasing attention [15-21]. Catalysts for the direct transformation of alcohols to esters are mostly based on noble metals (e.g., ruthenium, palladium, and gold) [22-30]. However, owing to the limited amounts of precious metals, the development of non-noble-metal-based catalysts for the direct oxidative esterification of alcohols is crucial from the perspectives of economic development and environmental protection. Moreover, with regard to catalyst separation and recycling, the employment of heterogeneous catalysts is more sustainable than that of homogeneous catalysts.

\footnotetext{
* Corresponding author. Tel/Fax: +86-371-23886876; E-mail: jyniu@henu.edu.cn

\# Corresponding author. Tel/Fax: +86-411-84379248; E-mail: sgao@dicp.ac.cn

This work was supported by the National Natural Science Foundation of China $(21773232,21403219,21773227)$.

DOI: 10.1016/S1872-2067(18)63058-X | http://www.sciencedirect.com/science/journal/18722067 | Chin. J. Catal., Vol. 39, No. 7, July 2018
} 
In recent years, carbon materials have become widely applied in many fields, including materials chemistry, chemical catalysis, and electrochemical catalysis, owing to their low costs, high stabilities, and excellent electrochemical performance [31-37]. Furthermore, the introduction of exotic atoms and metals can enhance the catalytic performance of pure carbon materials. This strategy is used to tune material compositions, entire electronic structures, and surface physicochemical properties to some extent, constructing new active sites and extending the application of carbonaceous materials to a wider range of organic syntheses [38-51]. Accordingly, cobalt-based $\mathrm{N}$-doped carbon materials have been proposed as potential cost-effective and environmentally benign catalysts for the direct aerobic oxidation of alcohols to esters [31,40,52,53].

In 2013, Beller et al. [53] prepared $\mathrm{Co}_{3} \mathrm{O}_{4}-\mathrm{N} @ \mathrm{C}$ with $\mathrm{Co}_{3} \mathrm{O}_{4}$ nanoparticle sizes in the range 2-80 $\mathrm{nm}$ by pyrolyzing cobalt salts and 1,10-phenanthroline adsorbed on Vulcan XC72R. This catalyst achieved the target reaction using $2.5 \mathrm{~mol} \%$ Co in $24 \mathrm{~h}$. In 2015, Jiang et al. [31] and Li et al. [52] almost simultaneously but separately employed ZIF-8-derived Co@C-N containing 15 mol\% Co to complete the synthesis of esters, with the latter group achieving base-free esterification at room temperature in $96 \mathrm{~h}$. Very recently, Li et al. [40] reported the preparation of a Mott-Schottky-type Co@NC catalyst through direct polycondensation of simple organic molecules and inorganic metal salts in the presence of $\mathrm{g}-\mathrm{C}_{3} \mathrm{~N}_{4}$ powder. However, the active cobalt species were poorly dispersed owing to the poor thermal stability of the small organic compounds and their random location on the carbon support. This unavoidable agglomeration of active cobalt species during pyrolysis greatly decreased the atomic catalytic efficiency of the resultant material. Notably, porous carbon materials are better catalytic carriers than non-porous materials owing to their large surface areas and diverse porous structures, which facilitate access to active sites and promote the transport of active oxygen species [54-56].

The design and preparation of efficient catalysts are essential activities in our field. Accordingly, we have previously fabricated mesoporous carbon materials derived from macrocyclic compounds and vitamin $\mathrm{B}_{12}$ that showed high activity in the formation of imines [57,58]. We also achieved the synthesis of nitriles using cobalt-modified $\mathrm{N}$-doped mesoporous carbon materials [59].

Encouraged by these results, in the present study we have applied cobalt-modified $\mathrm{N}$-doped mesoporous carbon (Co- $\mathrm{N} / \mathrm{m}-\mathrm{C}$ ) to the aerobic oxidative esterification of alcohols with air as a benign oxidant, achieving excellent catalytic activity, selectivity, and catalyst recyclability. This outstanding performance can be attributed to the robust ligand bridge that separates the cobalt ions and anchors them at the molecular level in the precursor, allowing uniform active-site distribution in the resultant catalyst at the sub-nano- or atomic scale. We demonstrate that the Co-N/m-C-900 catalyst, i.e., that prepared with pyrolysis at $900{ }^{\circ} \mathrm{C}$, is the most active for the target reaction. Moreover, the results of a preliminary recycling evaluation are reported, revealing that $\mathrm{Co}-\mathrm{N} / \mathrm{m}-\mathrm{C}-900$ can be used six times without significant loss of activity, thus demonstrating its excellent recyclability.

\section{Experimental}

\subsection{Materials}

11,11'-bis(Dipyrido[3,2-a:2',3'-c]phenazinyl (bidppz), and other reagents were obtained from commercial sources and used without further purification.

\subsection{Preparation of the Co- $\mathrm{N} / \mathrm{m}$-C catalyst}

To prepare the Co-N/m-C catalyst, $270 \mathrm{mg}$ bidppz and 122 $\mathrm{mg} \mathrm{Co}(\mathrm{OAc})_{2} \cdot 4 \mathrm{H}_{2} \mathrm{O}$ were added to $40 \mathrm{~mL}$ DMF under vigorous stirring. The mixture was then refluxed at $160^{\circ} \mathrm{C}$ for $2 \mathrm{~h}$. Then, $400 \mathrm{mg} \mathrm{SiO} 2$ (40 wt\% Ludox HS-40 colloidal silica) was added into the above mixture, which was vigorously stirred for another $3 \mathrm{~h}$. After evaporating the solvent at $180^{\circ} \mathrm{C}$, a composite of Co-bidppz and the template was obtained and then pyrolyzed at the desired temperature for $2 \mathrm{~h}$ under flowing nitrogen. The heating rate was $5{ }^{\circ} \mathrm{C} \cdot \mathrm{min}^{-1}$. Generally, Co- $\mathrm{N} / \mathrm{m}-\mathrm{C}$ catalyst was obtained upon removal of the template by washing with HF (10 wt \%) for $24 \mathrm{~h}$ under ambient atmosphere at room temperature.

\subsection{Characterization of catalysts}

$\mathrm{N}_{2}$ adsorption-desorption isotherms were measured using a QuadraSorb SI4 Station at $-196{ }^{\circ} \mathrm{C}$, and the samples were degassed at $300{ }^{\circ} \mathrm{C}$ for $6 \mathrm{~h}$ before measurement. Transmission electron microscopy (TEM) images were obtained using a JEM-2100 microscope. Scanning electron microscopy (SEM) images were obtained using a JSM-7800F microscope with an acceleration voltage of $20 \mathrm{kV}$. The Co loadings of the catalysts were measured using inductively coupled plasma atomic emission spectroscopy (ICP-AES) using a Perkin-Elmer OPTIMA 3300DV. The detection limit was $1.0 \times 10^{-7}$. Powder X-ray diffraction (XRD) patterns were collected on a Rigaku/Max-3A X-ray diffractometer using $\mathrm{Cu} K_{\alpha}$ radiation $(\lambda=1.54178 \AA$ ) . $\mathrm{X}$-ray photoelectron spectroscopy (XPS) analysis was conducted using a Thermo Scientific ESCALAB 250Xi with Al $K_{\alpha}$ radiation anode $(h v=1486.6 \mathrm{eV})$.

\subsection{Process for the synthesis of methyl benzoate}

A mixture of $22 \mathrm{mg} \mathrm{Co}-\mathrm{N} / \mathrm{m}-\mathrm{C}-900$ catalyst $(0.44 \mathrm{~mol} \% \mathrm{Co}$ ), $1 \mathrm{~mL}$ methanol, $0.5 \mathrm{mmol}$ of the corresponding alcohol, and 0.1 mmol potassium carbonate was added to a $10-\mathrm{mL}$ vial. The vial was placed into an autoclave, then the autoclave was filled with air to 1 bar. The mixture was stirred at $60{ }^{\circ} \mathrm{C}$ for $2 \mathrm{~h}$. After the reaction, the autoclave was removed and cooled to ambient temperature. The air inside the autoclave was discharged and the vial was removed from the autoclave, then biphenyl was added to the vial as a standard. The reaction solution was diluted with methanol, and then centrifuged and analyzed by gas chromatography (GC) and gas chromatography-mass spectrometry (GC-MS) quantitatively and qualitatively.

\subsection{Recycling of Co- $\mathrm{N} / \mathrm{m}-\mathrm{C}-900$}


The cycling test of the Co-N/m-C-900 catalyst was performed based on the model reaction of benzyl alcohol with methanol under the following reaction conditions: A mixture of $2 \mathrm{mmol}$ benzyl alcohol, $88 \mathrm{mg}$ Co-N/m-C-900, $4 \mathrm{~mL}$ methanol, and $0.4 \mathrm{mmol}$ potassium carbonate was transferred into a $50-\mathrm{mL}$ vial. The vial was placed into an autoclave and the autoclave was filled with $\mathrm{O}_{2}$ to 3 bar. The mixture was stirred at 60 ${ }^{\circ} \mathrm{C}$ for $2 \mathrm{~h}$. After the reaction, the autoclave was removed and cooled to ambient temperature. The air inside the autoclave was discharged and the vial was removed from the autoclave. The reaction solution was diluted with methanol, centrifuged, and then analyzed by GC and GC-MS. The catalyst was calcined at $400{ }^{\circ} \mathrm{C}$ for $2 \mathrm{~h}$ using a heating rate of $5{ }^{\circ} \mathrm{C} \cdot \mathrm{min}^{-1}$ in a nitrogen atmosphere and then applied to the next run. The conversion and yield of each run were confirmed by GC.

\subsection{Process for gram-scale reactions}

A mixture of $300 \mathrm{mg}$ Co-N/m-C-900 catalyst $(0.25 \mathrm{~mol} \%$ Co), $10 \mathrm{~mL}$ methanol, $10 \mathrm{mmol}$ benzyl alcohol, and $2 \mathrm{mmol}$ potassium carbonate was added to a $50-\mathrm{mL}$ vial. The vial was put into an autoclave and the autoclave was filled with $\mathrm{O}_{2}$ to 5 bar. The mixture was stirred at $80{ }^{\circ} \mathrm{C}$ for $24 \mathrm{~h}$. After the reaction, the autoclave was removed and cooled to ambient temperature. The $\mathrm{O}_{2}$ inside the autoclave was discharged and the vial was removed from the autoclave. The reaction solution was diluted with methanol, centrifuged, and analyzed by GC and GC-MS.

\section{Results and discussion}

We carried out a preliminary screening of different catalytic materials in order to identify the one with the highest catalytic performance using the reaction of benzyl alcohol with methanol as the model system. Generally, reactions were conducted at $60{ }^{\circ} \mathrm{C}$ using 1 bar $\mathrm{O}_{2}$. The results are shown in Table 1 . The blank experiment (not using any catalyst) demonstrates that

\section{Table 1}

Results obtained using different catalysts for the esterification of benzyl alcohol and methanol. a

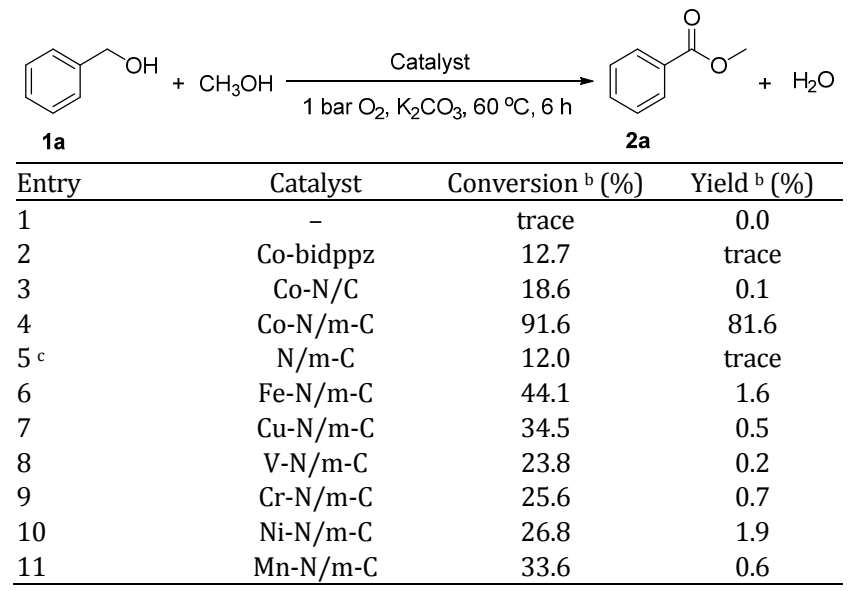

a Reaction conditions: catalyst ( $0.44 \mathrm{~mol} \%$ metal), $0.5 \mathrm{mmol}$ benzyl alcohol, $1 \mathrm{~mL} \mathrm{CH} \mathrm{CH}_{3} \mathrm{OH}, 0.2$ equiv $\mathrm{K}_{2} \mathrm{CO}_{3}, 1$ bar $\mathrm{O}_{2}, 6 \mathrm{~h}, 60^{\circ} \mathrm{C}$. b $\mathrm{GC}$ and GC-MS, using biphenyl as standard. . $50 \mathrm{mg}, 24 \mathrm{~h}, 60^{\circ} \mathrm{C}$. the reaction scarcely proceeds with no catalyst (Table 1, entry 1). Similarly, the Co-bidppz precursor shows little conversion of benzyl alcohol (Table 1, entry 2), confirming that, under the conditions studied, the Co-bidppz precursor is inactive in the target reaction. For comparison, we also directly pyrolyzed the Co-bidppz precursor without using a template. When the as-prepared low-surface-area Co-N/C catalyst $\left(227 \mathrm{~m}^{2} \cdot \mathrm{g}^{-1}\right.$, Fig. $\mathrm{S} 1$ ) is employed, the methyl benzoate yield barely reaches $0.1 \%$ (Table 1, entry 3). Gratifyingly, the Co- $\mathrm{N} / \mathrm{m}-\mathrm{C}$ catalyst shows excellent catalytic performance for this transformation, yielding the product in $81.6 \%$ yield (Table 1, entry 4). Consequently, we deduced that pyrolysis at high temperature was crucial for producing active sites and that the existence of porosity in the catalyst was important for promoting the reaction.

We also prepared a N/m-C catalyst without using cobalt acetate tetrahydrate by pyrolysis of bidppz using a silica colloid as a hard template for comparison. This catalyst was then applied to the model reaction. However, no activity for ester formation was observed (Table 1, entry 5). Thus, it may be inferred that the cobalt sites confer the catalytic activity to the material. Carbon materials fabricated with other non-noble transition metals provide lower conversions of benzyl alcohol than that achieved with cobalt (Table 1, entries 6-11). Thus, the $\mathrm{Co}-\mathrm{N} / \mathrm{m}-\mathrm{C}$ catalyst is the most active towards the direct esterification of benzyl alcohol with methanol. Consequently, we performed a series of exploratory experiments on the oxidative esterification of alcohols employing this Co-based catalyst.

To determine the optimum catalyst preparation temperature, catalysts prepared at different pyrolysis temperatures were utilized in the model reaction. As seen from Table 2, when the catalyst pyrolyzed at $900{ }^{\circ} \mathrm{C}$ is applied in the oxidative esterification of benzyl alcohol, it affords the target product methyl benzoate in $94.7 \%$ yield in only $2 \mathrm{~h}$, thus demonstrating the best activity and efficiency among the as-prepared catalysts (Table 2, entries 1-4). As the best catalyst in this work, Co-N/m-C-900 provides the high turnover frequency (TOF) of 107.6 mol methyl benzoate $\mathrm{mol}^{-1} \mathrm{Co} \mathrm{h}^{-1}$ for the direct oxidation of benzyl alcohol. This TOF value is an order of magnitude higher than the values reported for current Co-based heterogeneous catalysts, although the TOF value that obtained under base-free conditions over Co-N/m-C-900 is not the highest

Table 2

Co-N/m-C catalyzed esterification of benzyl alcohol and methanol. a

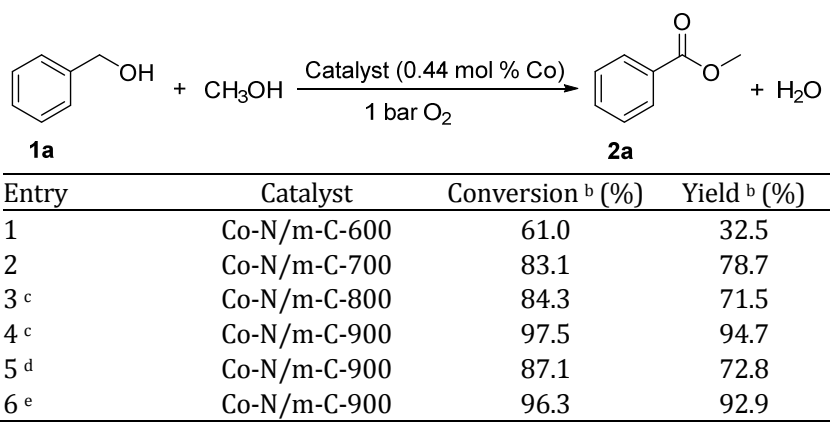

a Reaction conditions: $0.5 \mathrm{mmol} 1 \mathrm{a}, 1 \mathrm{~mL} \mathrm{CH} \mathrm{CH}_{3} \mathrm{OH}$, Co- $\mathrm{N} / \mathrm{m}-\mathrm{C}$ catalyst ( 0.44 mol\% Co), 0.2 equiv. $\mathrm{K}_{2} \mathrm{CO}_{3}, 1$ bar $\mathrm{O}_{2}, 3 \mathrm{~h}, 60^{\circ} \mathrm{C}$. ${ }^{\mathrm{b}} \mathrm{GC}$ and GC-MS, using biphenyl as standard. ${ }^{c} 2 \mathrm{~h}$. ${ }^{\mathrm{d}} 0.5 \mathrm{~h}$. $\mathrm{e} 1 \mathrm{bar}$ air, $2 \mathrm{~h}$. 
(Table S1, S2). Even within only $0.5 \mathrm{~h}$, the methyl benzoate yield reaches $72.8 \%$ (Table 2 , entry 5 ), which confirms the outstanding catalytic efficiency of our selected catalyst. Notably, this catalyst system is stable and can be reused at least five times. A yield of $92.9 \%$ is achieved when air is used as the oxidant (Table 2, entry 6), which is only a little lower than that in the presence of $\mathrm{O}_{2}$. Lower product yields are obtained in the presence of $\mathrm{Na}_{2} \mathrm{CO}_{3}$ and $\mathrm{NaOH}(58.6 \%-70.3 \%$, Table S3, entries 1 and 2), whereas $\mathrm{Cs}_{2} \mathrm{CO}_{3}, \mathrm{KOH}$, and $\mathrm{K}_{3} \mathrm{PO}_{4}$ provide slightly better yields (85.1\%-87.4\%; Table S3, entries 3-5). However, the highest yield is achieved with $\mathrm{K}_{2} \mathrm{CO}_{3}(92.9 \%$; Table S3, entry 6).

Thus, this systematic investigation revealed that the optimal reaction conditions were $22 \mathrm{mg}$ catalyst $(0.44 \mathrm{~mol} \% \mathrm{Co}), 0.2$ equiv. of $\mathrm{K}_{2} \mathrm{CO}_{3}$, and a reaction time of $2 \mathrm{~h}$ at $60{ }^{\circ} \mathrm{C}$ under air atmosphere. Furthermore, a very small amount of benzyl benzoate is detected after the reaction. Thus, we speculated that the catalyst might also catalyze the self-esterification of benzyl alcohol into benzyl benzoate. Consequently, we performed a self-esterification experiment with benzyl alcohol, and found that benzyl benzoate is indeed obtained (Table S4).

We performed thermogravimetric analysis to explore the relationship between the activity and structure of the catalysts. As shown in Fig. 1, the bidppz ligand exhibits very high thermal stability, with a total weight loss of only $24 \%$ at $900{ }^{\circ} \mathrm{C}$. However, the Co-bidppz coordination polymer exhibits significant weight loss at $250{ }^{\circ} \mathrm{C}$. When the temperature is further raised to $700{ }^{\circ} \mathrm{C}$, another weight loss occurs, bringing the total weight loss to $31 \%$. The experimental results given in Table 2 show that the catalytic activity of Co-N/m-C-700 is much higher than that of $\mathrm{Co}-\mathrm{N} / \mathrm{m}-\mathrm{C}-600$, indicating that most active sites are formed above $700{ }^{\circ} \mathrm{C}$. The Co contents of Co-N/m-C-600, 700, 800 , and 900 are $0.18,0.27,0.44$, and 0.59 wt $\%$, respectively, revealing that more active cobalt species are generated in the high-temperature range $\left(700-900^{\circ} \mathrm{C}\right)$. As discussed above, the highest activity in the target reaction is achieved over Co-N/m-C-900 samples.

$\mathrm{N}_{2}$ adsorption analysis was carried out to investigate the high catalytic activity of Co-N/m-C-900. The H4-type hysteresis

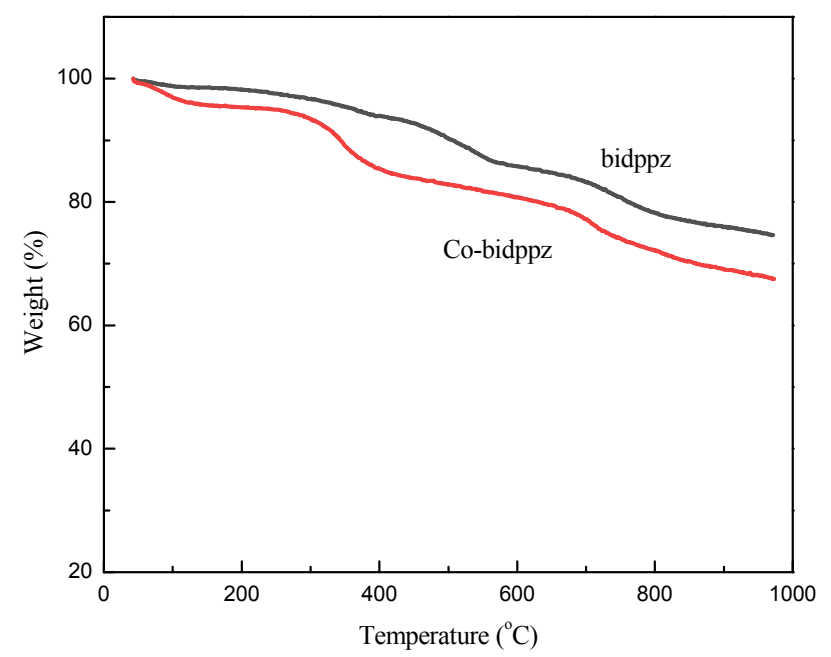

Fig. 1. Thermogravimetric curve of different precursors recorded under $\mathrm{N}_{2}$ atmosphere at a heating rate of $10^{\circ} \mathrm{C} \cdot \mathrm{min}^{-1}$.

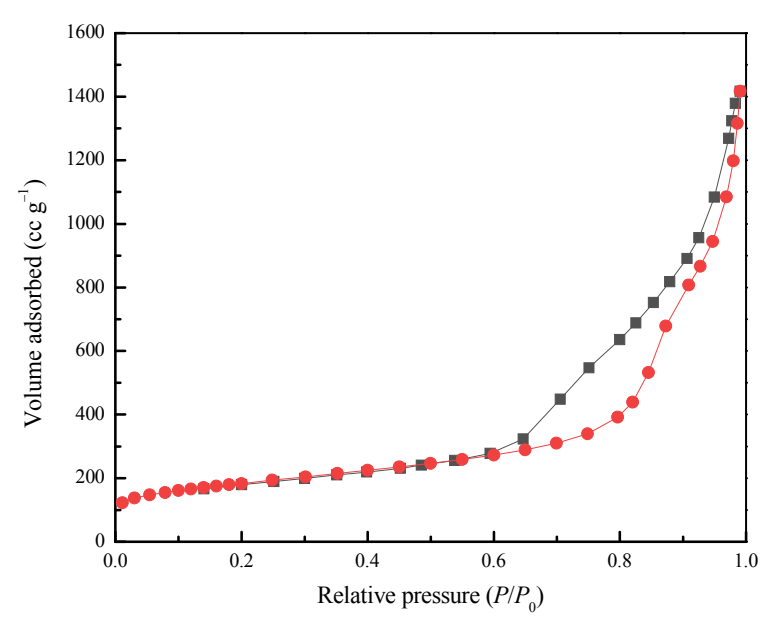

Fig. 2. $\mathrm{N}_{2}$ sorption isotherms for Co-N/m-C-900.

loop is powerful evidence for the mesoporous properties of the catalyst (Fig. 2). On the basis of the Barrett-Joyner-Halenda (BJH) model, Fig. 3 reveals a broad pore-size distribution for Co-N/m-C-900 ranging from 1.0 to $82.8 \mathrm{~nm}$, in which the primary pore size is $7.3 \mathrm{~nm}$. The Brunauer-Emmett-Teller (BET) surface areas of Co-N/m-C-700, Co-N/m-C-800, and Co-N/m-C-900 are 506, 680, and $641 \mathrm{~m}^{2} \cdot \mathrm{g}^{-1}$. Thus, the experimental results show that there is no positive correlation between catalyst activity and specific surface area. The mesoporous surface areas of Co-N/m-C-700, Co-N/m-C-800, Co-N/m-C-900 are 424, 523 and $502 \mathrm{~m}^{2} \cdot \mathrm{g}^{-1}$.

To explore the textural properties of the superior Co-based catalyst, the SEM analysis of Co-N/m-C-900 was conducted and the results are displayed in Fig. 4(a). A sponge-like surface morphology possessing a large number of dense pores is observed, clearly indicating the introduction of spherical holes in the prepared materials. We examined Co-N/m-C-900 using TEM to obtain further detailed structural information. Many pores are observed with pore sizes ranging from a few to several tens of nanometers, which agrees with the above SEM results and confirms the special porous structure of Co-N/m-C-900. No typical diffraction patterns are displayed in

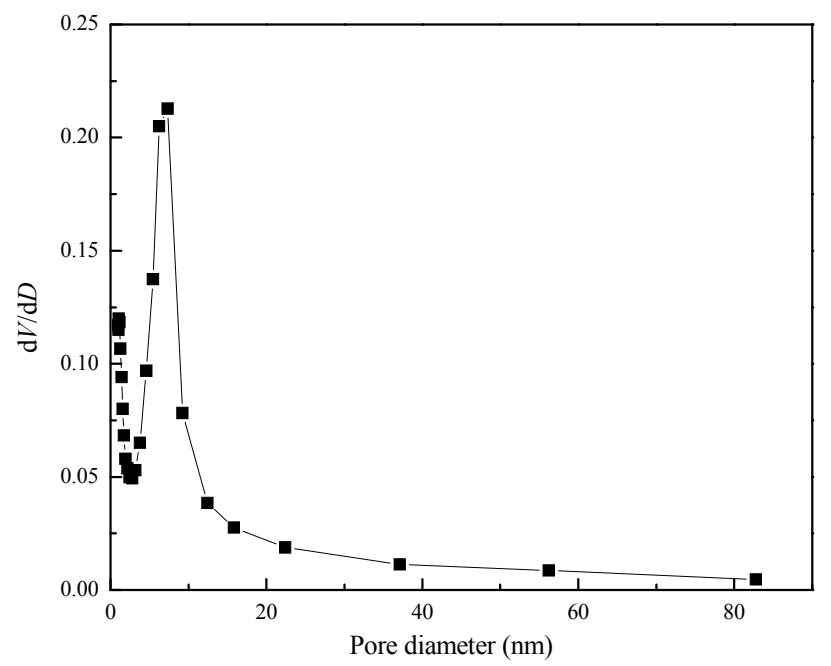

Fig. 3. BJH pore-size distribution plot for Co-N/m-C-900. 


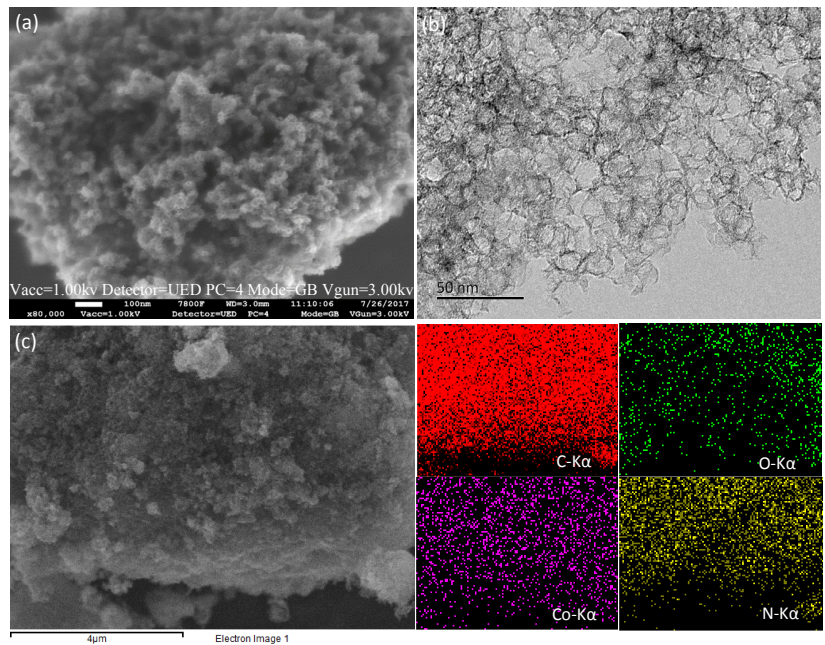

Fig. 4. Microstructural observation of the Co-N/m-C-900 catalyst (a) SEM image; (b) TEM image; (c) Large-area SEM image and the corresponding elemental maps.

the selected-area electron diffraction (SAED) image, which indicates the polycrystalline structure of the Co-N/m-C-900 sample (Fig. S2(c)). Moreover, the relevant energy-dispersive X-ray (EDX) spectrum displayed in Fig. S2(d) confirms the presence of cobalt. However, nanoparticles that contain metal could not be observed, even by HRTEM (Fig. S2(a) and Fig. S2(b)). To further verify this, SEM in backscattered electron detection mode $\left(\mathrm{V}_{\mathrm{acc}}=10.0 \mathrm{keV}\right.$, providing an electron penetration depth at the $\mu \mathrm{m}$ level) was employed (Fig. S3), and no white particles are seen. The absences of discernible metallic Co phase, $\mathrm{Co}_{3} \mathrm{O}_{4}$, and $\mathrm{CoO}$ species are further confirmed by the XRD results (Fig. S4). Metagenic chains consisting of the ligand and cobalt comprise the Co-bidppz polymer, which may impede the aggregation of cobalt species when the material is heated. Thus, it is rational to conjecture that, after acid washing, the vestigial active cobalt species might exist at the sub-nano- or atomic scale, which, along with the mesoporous microstructure of the catalyst, is responsible for its superior catalytic activity.

We performed XPS on the samples to determine the chemical states of the cobalt and nitrogen inside the Co- $\mathrm{N} / \mathrm{m}-\mathrm{C}$ cata-

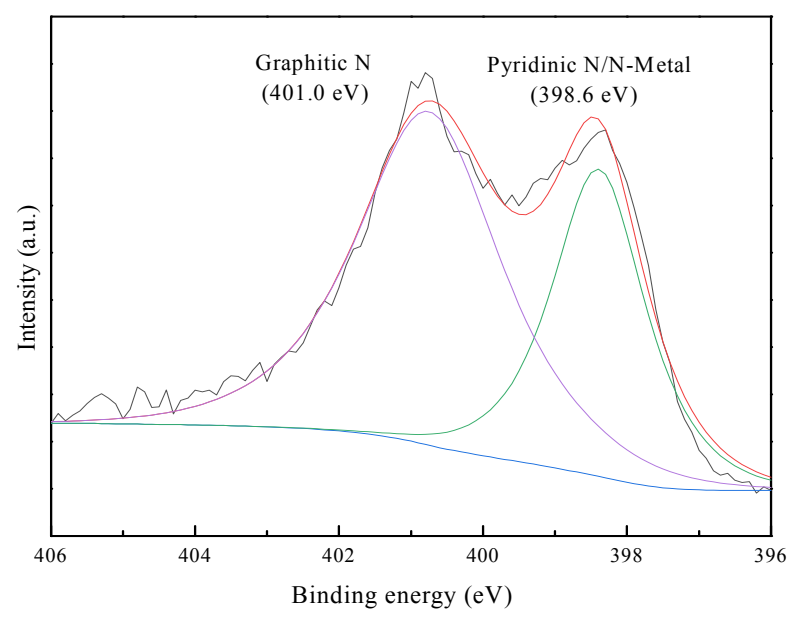

Fig. 5. N $1 s$ XPS spectra of Co-N/m-C-900.

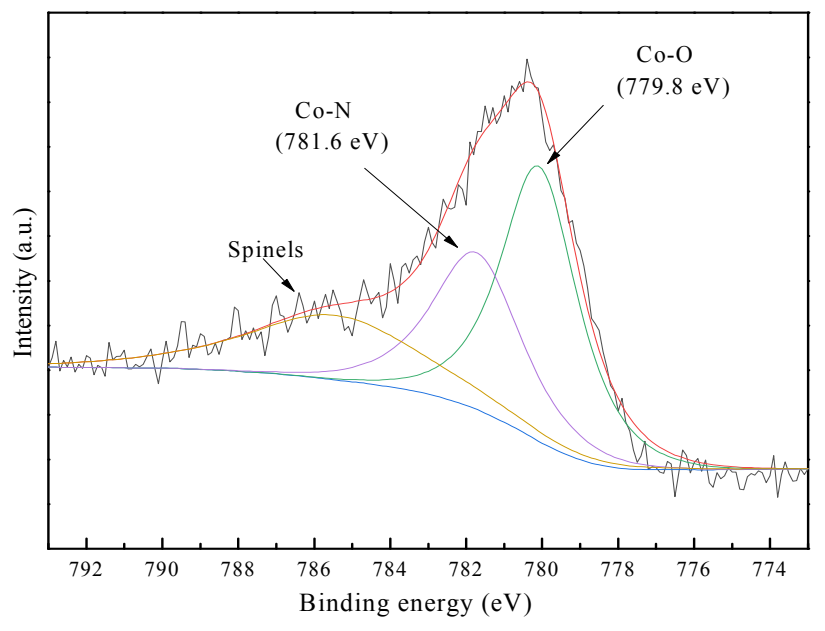

Fig. 6. Co $2 p_{3 / 2}$ XPS spectra of Co-N/m-C-900.

lysts (Fig. 5, Fig. 6, Fig. S5). The N $1 s$ spectrum of the catalyst could only be deconvoluted into two components, i.e., pyridinic nitrogen (398.6 eV) coordinating to a cobalt ion and graphitic nitrogen bonded with three $\mathrm{sp}^{2}$ carbon atoms within the graphitic plane (401.0 eV) (Fig. 5) [60,61]. Subsequently, the Co $2 p_{3 / 2}$ XPS spectrum of the Co-N/m-C-900 catalyst was fitted into two distinct peaks centered at 781.6 and $779.8 \mathrm{eV}$ (Fig. 6), which can be ascribed to Co-N and Co-0, respectively [62]. As shown in Fig. S6 and S7, the specific forms of the nitrogen dopants and cobalt in Co-N/m-C-700 and -800 are the same as those in $\mathrm{Co}-\mathrm{N} / \mathrm{m}-\mathrm{C}-900$. Many researchers have shown that the special Co chemical environment, in which pyridinic nitrogen is involved, plays an important part in furnishing the catalysts with appropriate activity in oxidation reactions. Furthermore, the $\mathrm{N}$-doped carbon also helps stabilize the active Co species $[53,63,64]$.

The proposed methodology exhibits general applicability to the esterification of other aromatic alcohols. Diverse benzylic alcohols are oxidized selectively to the corresponding methyl esters in good to excellent yields at $60{ }^{\circ} \mathrm{C}$ (Table 3). Benzyl alcohols and alkyl-substituted benzyl alcohols are esterified conveniently in high yields of up to $98.8 \%$ (Table 3, entries 1-5), and benzyl alcohols substituted with other electron-donating groups such as $-\mathrm{OCH}_{3}$ in the para- and meta-positions give the corresponding methyl benzoates in $96.4 \%$ and $91.5 \%$ yields (Table 3, entries 6 and 7). In addition, substrates with halogen functional groups $(-\mathrm{F},-\mathrm{Cl},-\mathrm{Br})$ are esterified to the target methyl esters in high yields (Table 3, entries 9-11). When the benzyl alcohol is substituted with a strong electron-withdrawing group $\left(-\mathrm{NO}_{2}\right.$ and $\left.-\mathrm{CF}_{3}\right)$ in the para-position, slightly lower yields of the corresponding products are obtained (Table 3, entries 12 and 13).

Based on the above results, benzyl alcohols substituted with electron-donating and electron-withdrawing functional groups are esterified to the desired methyl esters in satisfactory yields. It is worthy of note that the more sensitive allylic alcohol is also moderately converted to the corresponding ester in our oxidative esterification system, providing the methyl cinnamate in $80 \%$ yield (Table 3 , entry 14 ). 
Table 3

Co-N/m-C-900 catalyzed esterification of aromatic alcohols and methanol. ${ }^{a}$

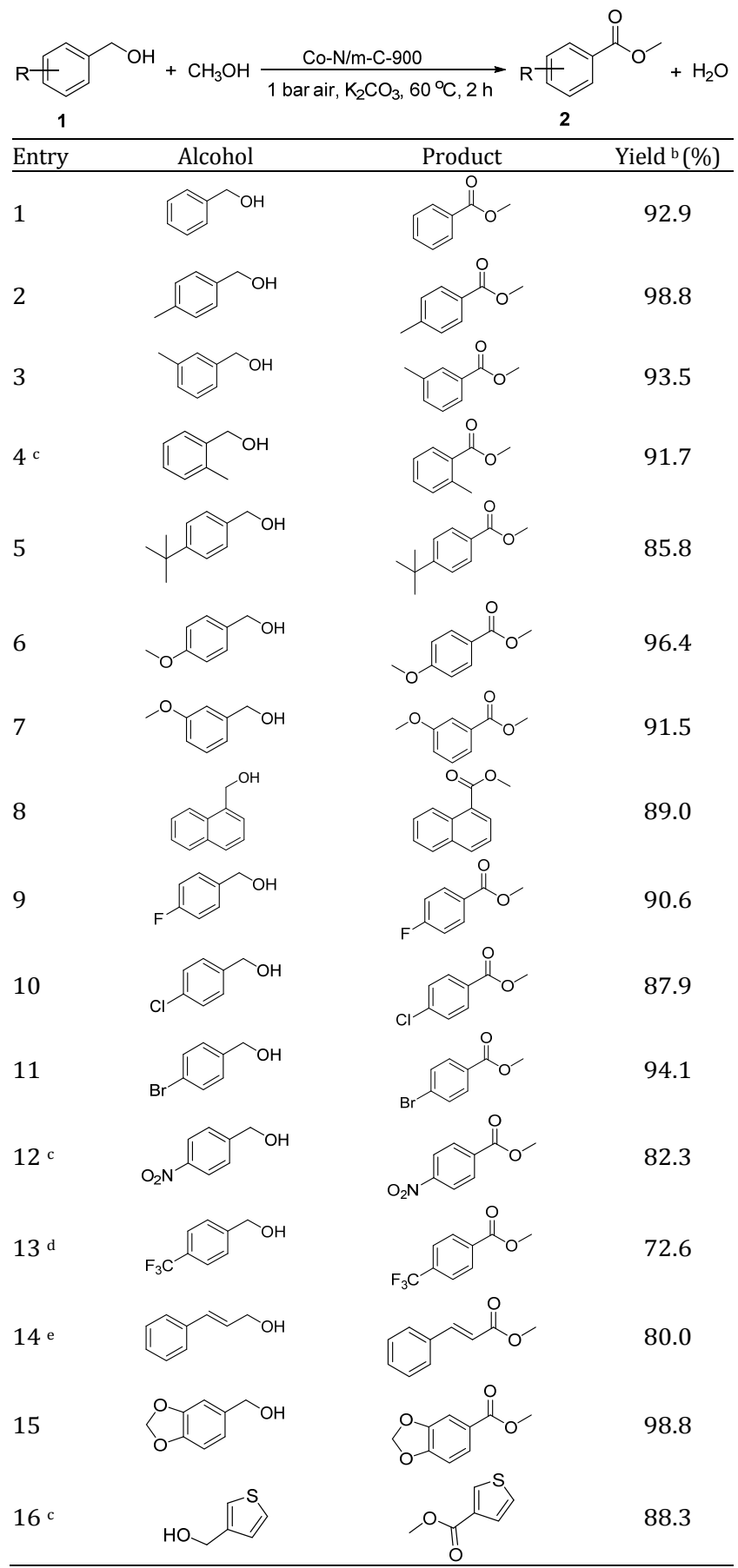

a Reaction conditions: Co-N/m-C-900 catalyst (22 mg, $0.44 \mathrm{~mol} \% \mathrm{Co}$ ), 0.5 mmol 1, 0.2 equiv. $\mathrm{K}_{2} \mathrm{CO}_{3}, 1 \mathrm{~mL}$ methanol, 1 bar air, $2 \mathrm{~h}, 60^{\circ} \mathrm{C}$. b $\mathrm{GC}$ and GC-MS. ${ }^{\mathrm{c}} 6 \mathrm{~h}, 80^{\circ} \mathrm{C}$, d $16 \mathrm{~h}, 80^{\circ} \mathrm{C}$, e $12 \mathrm{~h}, 60^{\circ} \mathrm{C}$

Next, we studied the oxidative esterification of heterocyclic alcohols. Piperonyl alcohol is transformed into methyl 1,3-benzodioxole-5-carboxylate in the excellent yield of $98.8 \%$ (Table 3, entry 15), and the esterification of 3-thienylmethanol gives the product in the satisfactory yield of $88.3 \%$ (Table 3 , entry 16).

After obtaining satisfactory results for the esterification of
Table 4

Co-N/m-C-900 catalyzed esterification of benzylic alcohols and aliphatic alcohols. a

Entry
${^{\prime}-\mathrm{OH}} }$

$2 \widehat{\mathrm{OH}}$

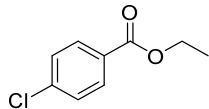

90

$3^{\mathrm{c}} \widehat{\mathrm{OH}}$<smiles>CCOC(=O)c1ccc(C)cc1</smiles>

90

$4^{\mathrm{d}} \widehat{\mathrm{OH}}_{\mathrm{OH}}$

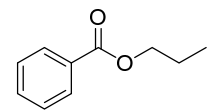

90

79.1

$5^{\mathrm{d}} \curvearrowright \overbrace{\mathrm{OH}}$<smiles>CCCCOC(=O)c1ccccc1</smiles>

110

$6^{\mathrm{d}} \overbrace{\mathrm{OH}}$<smiles>O=[Co]</smiles>

a Reaction conditions: Co-N/m-C-900 catalyst (22 mg, $0.44 \mathrm{~mol} \% \mathrm{Co}$ ), $0.5 \mathrm{mmol}$ benzylic alcohol, 0.5 equiv. $\mathrm{K}_{2} \mathrm{CO}_{3}, 1$ bar air, $1 \mathrm{~mL} \mathrm{R'-OH}, 6 \mathrm{~h}$.

b GC and GC-MS. ${ }^{c} 0.8$ equiv. $\mathrm{K}_{2} \mathrm{CO}_{3}$. ${ }^{\mathrm{d}} 1$ equiv. $\mathrm{K}_{2} \mathrm{CO}_{3}, 24 \mathrm{~h}$.

various benzylic alcohols with methanol, we explored the selective oxidative coupling with other aliphatic alcohols. In fact, very little research has been carried out for such cross-esterifications, i.e., when one alcohol has the possibility of being oxidized in the presence of another. As expected, benzylic alcohols and ethanol are transformed into the corresponding ethyl esters in $70.0 \%-78.3 \%$ yield (Table 4 , entries $1-3$ ). For propyl, butyl, and pentyl alcohols, the desired esters are obtained in $71.8 \%-87.4 \%$ yield (Table 4 , entries $4-6$ ).

As we all know, stability and recyclability are crucial criteria for the practical application of heterogeneous catalytic materials. Thus, in order to demonstrate its reusability, six consecutive oxidative esterifications of benzyl alcohol with methanol were performed using the Co- $\mathrm{N} / \mathrm{m}-\mathrm{C}-900$ catalyst. In this experiment, the catalyst was washed thoroughly with methanol after the reaction was over, and it was then calcined at $400{ }^{\circ} \mathrm{C}$ under $\mathrm{N}_{2}$ for $2 \mathrm{~h}$ before being employed in the next run. The results revealed that the $\mathrm{Co}-\mathrm{N} / \mathrm{m}-\mathrm{C}-900$ catalyst can be recycled successfully five times with no apparent loss of catalytic activity (Fig. 7).

The catalytic experiments above were conducted at the 0.5-2 mmol scale. Therefore, we were interested in exploring the synthetic utility of this methodology in terms of scale-up. Therefore, we performed reactions for some substrates at the $10 \mathrm{mmol}$ scale. As shown in Scheme 1, the corresponding methyl esters are obtained in yields of up to $96.1 \%$. Thus, our catalyst system is applicable to the lab-scale direct esterification of alcohols in relatively short reaction times using air as a benign oxidant. 


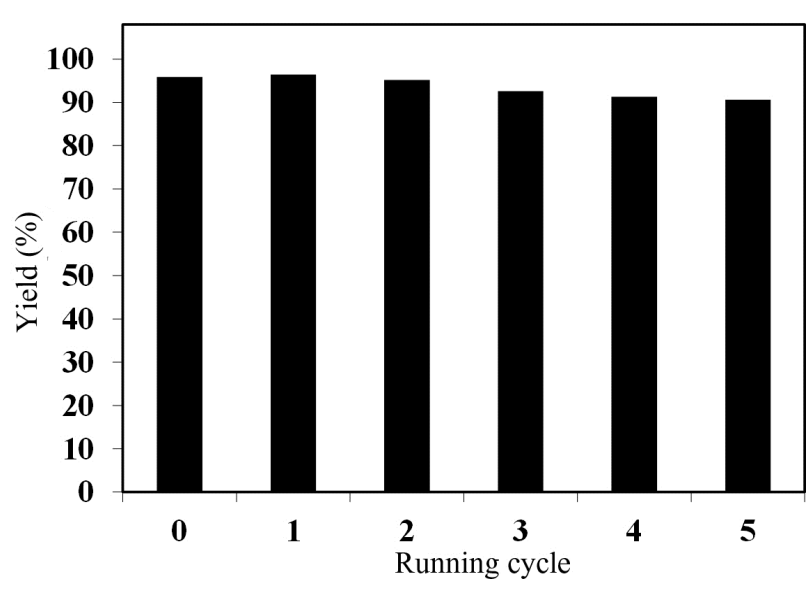

Fig. 7. Recyclability of $\mathrm{Co}-\mathrm{N} / \mathrm{m}-\mathrm{C}-900$ catalyst. Reaction conditions: catalyst ( $88 \mathrm{mg}, 0.44 \mathrm{~mol} \% \mathrm{Co}$ ), $2 \mathrm{mmol}$ benzyl alcohol, $4 \mathrm{~mL}$ methanol, 0.2 equiv. $\mathrm{K}_{2} \mathrm{CO}_{3}, 3$ bar $\mathrm{O}_{2}, 2 \mathrm{~h}, 60^{\circ} \mathrm{C}$.

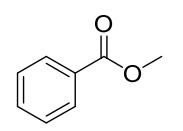

$96.1 \%$

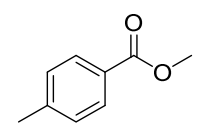

$92.9 \%$

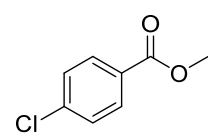

$92.0 \%$

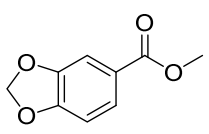

$95.1 \%$
Scheme 1. Gram-scale reaction yields. Reaction conditions: $10 \mathrm{mmol}$ benzylic alcohol, 0.2 equiv. $\mathrm{K}_{2} \mathrm{CO}_{3}$, catalyst ( $300 \mathrm{mg}, 0.30 \mathrm{~mol} \% \mathrm{Co}$ ), 10 $\mathrm{mL}$ methanol, 5 bar $\mathrm{O}_{2}, 24 \mathrm{~h}, 80^{\circ} \mathrm{C}$, GC and GC-MS.

\section{Conclusions}

We have developed an efficient and inexpensive strategy for the direct oxidative esterification of alcohols to produce esters under mild conditions using a cobalt-modified N-doped mesoporous carbon catalyst (Co-N/m-C-900). The catalyst is fabricated by pyrolysis of a Co-bidppz/template composite followed by removal of the template with $\mathrm{HF}$, and it exhibits high catalytic activity for a broad scope of substrates with various functional groups. Moreover, the catalyst can be easily recovered and recycled at least five times with no apparent loss in activity. Thus, this strategy may provide new avenues for the development of durable and efficient catalysts for highly efficient catalytic organic transformations.

\section{References}

[1] J. Otera, J. Nishikido, Esterification: Methods, Reactions, and Applications, Wiley: Hoboken, NJ, 2009, p1.

[2] J. D. Nguyen, E. M. D'Amato, J. M. R. Narayanam, C. R. J. Stephenson, Nat. Chem. 2012, 4, 854-859.

[3] A. Brennführer, H. Neumann, M. Beller, Angew. Chem. Int. Ed., 2009, 48, 4114-4133.

[4] W. Mägerlein, M. Beller, A. F. Indolese, J. Mol. Catal. A, 2000, 156, 213-221.

[5] R. C. Larock, Comprehensive Organic Transformations: A Guide to Functional Group Preparations, Wiley-VCH, New York, 2nd ed, 1999, 1, 1-2640.

[6] D. H. Nguyen, X. Trivelli, F. Capet, J. F. Paul, F. Dumeignil, R. M. Gauvin, ACS Catal., 2017, 7, 2022-2032.

[7] D. Q. Dong, H. Zhang, Z. L. Wang, RSC Adv., 2017, 7, 3780-3782.

[8] S. Verma, R. B. N. Baig, C. Han, M. N. Nadagouda, R. S. Varma, Green Chem., 2016, 18, 251-254.

[9] R. Ray, R. D. Jana, M. Bhadra, D. Maiti, G. K. Lahiri, Chem. Eur. J., 2014, 20, 15618-15624.

[10] K. Suzuki, T. Yamaguchi, K. Matsushita, C. Iitsuka, J. Miura, T. Akaogi, H. Ishida, ACS Catal., 2013, 3, 1845-1849.

[11] E. G. Delany, C. L. Fagan, S. Gundala, A. Mari, T. Broja, K. Zeitler, S. J. Connon, Chem. Commun., 2013, 49, 6510-6512.

[12] X. F. Wu, H. Neumann, M. Beller, ChemCatChem, 2010, 2, 509-513.

[13] G. E. Dobereiner, R. H. Crabtree, Chem. Rev., 2010, 110, 681-703.

[14] R. Gopinath, B. K. Patel, Org. Lett., 2000, 2, 577-579.

[15] T. Tana, X. W. Guo, Q. Xiao, Y. M. Huang, S. Sarina, P. Christopher, J. F. Jia, H. S. Wu, H. Y. Zhu, Chem. Commun., 2016, 52, 11567-11570.

[16] S. E. Davis, M. S. Ide, R. J. Davis, Green Chem., 2013, 15, 17-45.

[17] X. F. Wu, Chem. Eur. J., 2012, 18, 8912-8915.

[18] M. Nielsen, H. Junge, A. Kammer, M. Beller, Angew. Chem. Int. Ed., 2012, 51, 5711-5713.

[19] K. Kaizuka, H. Miyamura, S. Kobayashi, J. Am. Chem. Soc., 2010, 132, 15096-15098.

[20] R. L. Oliveira, P. K. Kiyohara, L. M. Rossi, Green Chem., 2009, 11, 1366-1370.

[21] N. A. Owston, A. J. Parker, J. M. J. Williams, Chem. Commun., 2008, 624-625.

[22] L. L. Chng, J. H. Yang, J. Y. Ying, ChemSusChem, 2015, 8, 1916-1925.

[23] L. Y. Wang, J. Li, W. Dai, Y. Lv, Y. Zhang, S. Gao, Green Chem., 2014, $16,2164-2173$.

[24] M. Caporaso, G. Cravotto, S. Georgakopoulos, G. Heropoulos, K. Martina, S. Tagliapietra, Beilstein J. Org. Chem., 2014, 10,

\section{Graphical Abstract}

Chin. J. Catal., 2018, 39: 1249-1257 doi: 10.1016/S1872-2067(18)63058-X

\section{Superior performance of Co-N/m-C for direct oxidation of alcohols to esters under air}

Ning Li, Sensen Shang, Lianyue Wang, Jingyang Niu*, Ying Lv, Shuang Gao* Henan University; Dalian Institute of Chemical Physics, Chinese Academy of Sciences

We report an expeditious and eco-efficient methodology for the synthesis of esters by aerobic oxidative esterification of readily available alcohols using a cobalt-modified $\mathrm{N}$-doped mesoporous carbon material $(\mathrm{Co}-\mathrm{N} / \mathrm{m}-\mathrm{C})$ as the catalyst under air atmosphere.

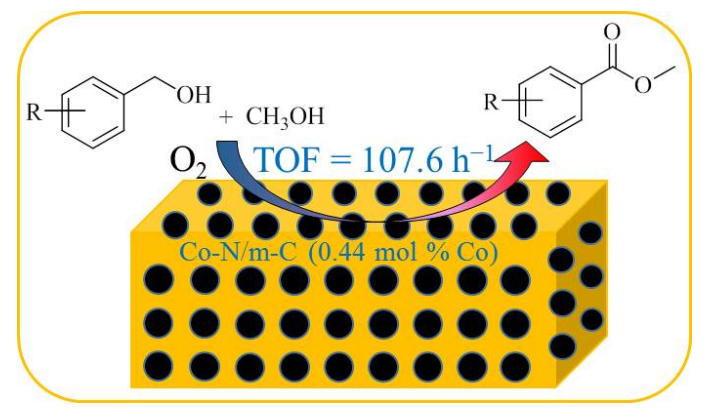


1454-1461.

[25] C. Liu, S. Tang, A. W. Lei, Chem. Commun., 2013, 49, 1324-1326.

[26] C. Liu, J. Wang, L. K. Meng, Y. Deng, Y. Li, A. W. Lei, Angew. Chem. Int. Ed., 2011, 50, 5144-5148.

[27] S. Gowrisankar, H. Neumann, M. Beller, Angew. Chem. Int. Ed., 2011, 50, 5139-5143.

[28] H. Miyamura, T. Yasukawa, S. Kobayashi, Green Chem., 2010, 12, 776-778.

[29] C. Gunanathan, L. J. W. Shimon, D. Milstein, J. Am. Chem. Soc., 2009, 131, 3146-3147.

[30] J. Zhang, G. Leitus, Y. Ben-David, D. Milstein, J. Am. Chem. Soc., 2005, 127, 10840-10841.

[31] Y. X. Zhou, Y. Z. Chen, L. N. Cao, J. L. Lu, H. L. Jiang, Chem. Commun., 2015, 51, 8292-8295.

[32] J. Zhu, A. Holmen, D. Chen, ChemCatChem, 2013, 5, 378-401.

[33] P. Serp, E. Castillejos, ChemCatChem, 2010, 2, 41-47.

[34] R. L. Liu, D. Q. Wu, X. L. Feng, K. Müllen, Angew. Chem. Int. Ed., 2010, 49, 2565-2569.

[35] L. L. Zhang, X. S. Zhao, Chem. Soc. Rev., 2009, 38, 2520-2531.

[36] E. Frackowiak, Phys. Chem. Chem. Phys., 2007, 9, 1774-1785.

[37] A. G. Pandolfo, A. F. Hollenkamp, J. Power Sources, 2006, 157, 11-27.

[38] J. F. Liang, X. M. Zhang, L. Y. Jing, H. Q. Yang, Chin. J. Catal., 2017, 38, $1252-1260$.

[39] B. Han, R. Lang, B. T. Qiao, A. Q. Wang, T. Zhang, Chin. J. Catal., 2017, 38, 1498-1507.

[40] H. Su, K. X. Zhang, B. Zhang, H. H. Wang, Q. Y. Yu, X. H. Li, M. Antonietti, J. S. Chen, J. Am. Chem. Soc., 2017, 139, 811-818.

[41] X. Lin, Z. Z. Nie, L. Y. Zhang, S. C. Mei, Y. Chen, B. S. Zhang, R. L. Zhu, Z. G. Liu, Green Chem., 2017, 19, 2164-2173.

[42] L. L. Zhang, A. Q. Wang, W. T. Wang, Y. Q. Huang, X. Y. Liu, S. Miao, J. Y. Liu, T. Zhang, ACS Catal., 2015, 5, 6563-6572.

[43] A. V. Iosub, S. S. Stahl, Org. Lett., 2015, 17, 4404-4407.

[44] X. J. Cui, Y. H. Li, S. Bachmann, M. Scalone, A. E. Surkus, K. Junge, C. Topf, M. Beller, J. Am. Chem. Soc., 2015, 137, 10652-10658.

[45] P. Tang, Y. J. Gao, J. H. Yang, W. J. Li, H. B. Zhao, D. Ma, Chin. J. Catal., 2014, 35, 922-928.

[46] R. V. Jagadeesh, H. Junge, M. Beller, Nat. Commun., 2014, 5, 4123.

[47] D. Banerjee, R. V. Jagadeesh, K. Junge, M. M. Pohl, J. Radnik, A.
Brückner, M. Beller, Angew. Chem. Int. Ed., 2014, 53, 4359-4363.

[48] R. V. Jagadeesh, A. E. Surkus, H. Junge, M. M. Pohl, J. Radnik, J. Rabeah, H. M. Huan, V. Schünemann, A. Brückner, M. Beller, Science, 2013, 342, 1073-1076.

[49] H. L. Peng, Z. Y. Mo, S. J. Liao, H. G. Liang, L. J. Yang, F. Luo, H. Y. Song, Y. L. Zhong, B. Q. Zhang, Sci. Rep., 2013, 3, 1765-1771.

[50] C. H. Bai, X. F. Yao, Y. W. Li, ACS Catal., 2015, 5, 884-891.

[51] Y. B. Huang, M. Zhang, P. Liu, F. L. Cheng, L. S. Wang, Chin. J. Catal., 2016, 37, 1249-1256.

[52] W. Zhong, H. L. Liu, C. H. Bai, S. J. Liao, Y. W. Li, ACS Catal., 2015, 5, 1850-1856.

[53] R. V. Jagadeesh, H. Junge, M. M. Pohl, J. Radnik, A. Brückner, M. Beller, J. Am. Chem. Soc., 2013, 135, 10776-10782.

[54] L. Qie, W. M. Chen, Z. H. Wang, Q. G. Shao, X. Li, L. X. Yuan, X. L. Hu, W. X. Zhang, Y. H. Huang, Adv. Mater., 2012, 24, 2047-2050.

[55] T. Kyotani, Carbon, 2000, 38, 269-286.

[56] J. W. Patrick, Porosity in Carbons: Characterization and Applications, Wiley, London, 1995, 49-291.

[57] B. Chen, S. S. Shang, L. Y. Wang, Y. Zhang, S. Gao, Chem. Commun., 2016, 52, 481-484.

[58] B. Chen, L. Y. Wang, W. Dai, S. S. Shang, Y. Lv, S. Gao, ACS Catal., 2015, 5, 2788-2794.

[59] S. S. Shang, L. Y. Wang, W. Dai, B. Chen, Y. Lv, S. Gao, Catal. Sci. Technol., 2016, 6, 5746-5753.

[60] F. A. Westerhaus, R. V. Jagadeesh, G. Wienhöfer, M. M. Pohl, J. Radnik, A. E. Surkus, J. Rabeah, K. Junge, H. Junge, M. Nielsen, A. Brückner, M. Beller, Nat. Chem., 2013, 5, 537-543.

[61] F. Jaouen, J. Herranz, M. Lefèvre, J. P. Dodelet, U. I. Kramm, I. Herrmann, P. Bogdanoff, J. Maruyama, T. Nagaoka, A. Garsuch, J. R. Dahn, T. Olson, S. Pylypenko, P. Atanassov, E. A. Ustinov, ACS Appl. Mater. Interfaces, 2009, 1, 1623-1639.

[62] G. Wu, Z. W. Chen, K. Artyushkova, F. H. Garzon, P. Zelenay, ECS Trans., 2008, 16, 159-170.

[63] J. Deng, H. J. Song, M. S. Cui, Y. P. Du, Y. Fu, ChemSusChem, 2014, 7, 3334-3340.

[64] R. F. Nie, J. J. Shi, W. C. Du, W. S. Ning, Z. Y. Hou, F. S. Xiao, J. Mater. Chem. A, 2013, 1, 9037-9045.

\title{
Co-N/m-C 高效催化空气下醇直接氧化成酯
}

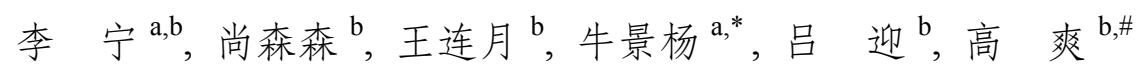

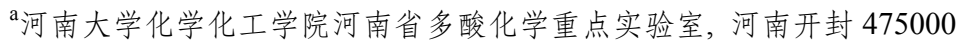 \\ b国科学院大连化学物理研究所, 辽宁大连 116023
}

摘要: 酯类在有机合成中作为基础材料广泛地应用于精细化学品, 农用化学品, 药物等的生产中. 传统生产酯的方法需要 用到羧酸, 酸䣶, 酰卤或酮类, 并经过多步反应完成. 往往会造成原材料的浪费, 并伴随副产物的产生. 因此用醇代替酸或 其衍生物与另一种醇反应直接氧化酯化合成相应的酯具有很大的经济意义. 目前已有基于贵金属(如钓, 钯和金)的将醇类 直接氧化为酯类的催化剂的研究, 但是贵金属的价格及其有限的资源限制了其在实际生产中的应用. 从经济发展和环境 保护的角度出发, 开发基于非贵金属的用于醇氧化酯化的催化剂有重要意义.

近年来, 碳材料由于成本低、稳定性高、电化学性能优异的特点而广泛应用于材料、化学催化和电化学催化等领 域. 此外, 杂原子和金属的引入可以在一定程度上调节材料的组成, 电子结构和表面物理化学性质而进一步构建新的活性 位点, 增强碳材料的催化性能. 另外, 由于多孔碳材料具有较大的比表面积和多样的孔结构, 作为催化剂载体比普通碳材 料更优越, 使得底物更容易接触活性部位, 同时提高氧的传输能力. 然而, 活性钴物种因在热解过程中容易发生团聚而使 原子催化效率降低. 因此设计和制备高分散且高效的催化剂对于实现醇氧化为酯有重要意义. 
钴基氮掺杂碳材料是一种有潜力的能将醇直接氧化到酯的经济, 高效, 环保的催化剂. 本文提出了一种方便, 快捷, 高 效的醇直接氧化成酯的方法, 即利用直接热解大分子前驱体制备钴改性 $N$ 掺杂介孔碳材料 $(\mathrm{Co}-\mathrm{N} / \mathrm{m}-\mathrm{C})$, 用于醇直接氧化成 酯反应中, 其中以 $900{ }^{\circ} \mathrm{C}$ 下焙烧所制的催化剂活性最高. 该催化剂对于苯甲醇直接有氧氧化成苯甲酸甲酯反应的TOF值高 达 $107.6 \mathrm{~h}^{-1}$, 远高于目前所报道的过渡金属基纳米催化剂的, 这得益于超分散钴物种与材料中吡啶氮之间的强配位作用及 大的介孔比表面积. 对于不同结构的醇, 包括苄基醇, 烯丙基醇和杂环醇, 也能高收率地得到相应酯, 说明该催化剂具有普 适性. 另外, Co-N/m-C-900催化剂经循环使用六次后没有显著的活性损失, 表明了该催化剂具有一定的稳定性.

关键词: 钴; 氮掺杂; 介孔碳材料; 酯; 催化

收稿日期: 2018-01-09. 接受日期: 2018-02-24. 出版日期: 2018-07-05.

*通讯联系人. 电话/传真: (0371)23886876; 电子信箱: jyniu@henu.edu.cn

通讯联系人. 电话/传真: (0411)84379248; 电子信箱: sgao@dicp.ac.cn

基金来源：国家自然科学基金 $(21773232,21403219,21773227)$.

本文的电子版全文由Elsevier出版社在ScienceDirect上出版(http://www.sciencedirect.com/science/journal/18722067). 